\section{Best of the Best Business Websites}

\section{BRASS Education Committee}

BRASS Education Committee members: Ashley E. Faulkner, Co-Chair; Robbi De Peri, Co-Chair; Charles Allan; Cara Margaret Cadena; Phebe L. Dickson; Bridget Farrell; LuMarie Guth; Monica J. Hagan; Sara Foster Hess; Hiromi Kubo; Kelly LaVoice; Thomas J. Ottaviano; Christina M. Sheley; Eimmy K. Solis; Andy Spackman; and, Teresa Denise Williams.

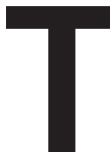

he Best of the Best Business Websites Award was established in 2009 to recognize three websites relevant to information professionals providing business reference services. The websites are nominated and selected by the Business Reference and Services Section (BRASS) Education Committee members on the basis of their content quality, ease of use and technical execution. The winners are announced at the RUSA Book and Media Awards reception at the ALA Midwinter Meeting. You may view previous winners at www.ala.org/rusa/awards/bestofthe bestbus. To access other BRASS-recommended resources, go to http://brass.libguides.com

\section{BEST FREE BUSINESS WEBSITES WINNERS}

\section{Topic: Business Data}

American FactFinder: factfinder.census.gov

The Census Bureau collects and disseminates data about the United States population and economy, conducting more than 130 surveys and censuses a year. As the official search tool of the Census Bureau, American FactFinder allows users to tap into some of the most popular data the Census Bureau collects, providing invaluable insight into communities around the country. A list of all the surveys and censuses conducted by the Census Bureau can be found on their website (www.census.gov/programs-surveys/surveys -programs.html).

The sheer quantity of free data available via American FactFinder is its greatest strength. Few other resources explore the population and economy of the United States in such depth as American FactFinder, and even fewer do so with no cost to the user. Perhaps the most well-known product of the Census Bureau, the once-a-decade Decennial Census is included in American Factfinder, but other surveys and censuses that capture more up-to-date changes in the United States population are also searchable through the tool, such as the American Community Survey, American Housing Survey, data from the Population Estimates Program, and the Puerto Rico Community Survey. American Factfinder can also be used to find information on United States businesses and industries with data from the Census Bureau's Annual Economic Surveys and the Economic Census, conducted every five years. Finally, data from the Census of Governments, conducted every five years, is available through American FactFinder for data on state and local government units. A list of these and other surveys and censuses included 


\section{FROM COMMITTEES OF RUSA}

in American Factfinder can be found on its website (http:// factfinder.census.gov/faces/nav/jsf/pages/what_we_provide .xhtml). Data covers the entire United States, from countrywide and state level data to county, metropolitan areas, and census block groups. It is important to note, however, that for smaller geographic locations there is at times less (or no) data available, either to protect the anonymity of survey/ census respondents, or because data simply is not collected for that variable at that level.

To access data in American FactFinder, researchers are given several interfaces to choose from, all of which are accessible through the landing page of the American FactFinder website. The Community Facts interface is perfect for quick statistics about single communities (e.g., state, county, city or zip code). For more in-depth questions that require comparing multiple geographies, the Guided Search and Advanced Search interfaces allow researchers to build a search using topics, geographies, race and ethnic group, and industry codes. The Guided Search takes researchers through the steps of choosing variables, while the Advanced Search allows researchers to search for tables by keyword. Another interface, the Download Center, allows researchers to quickly find datasets or tables-perfect if someone knows the exact name of the dataset or table they need.

Data in American FactFinder is primarily visualized through tables, though when comparing two or more geographies users are also given the option to create a map to represent the data. Tables can be saved to a variety of file formats, allowing easy exporting to both Microsoft Excel and PDF. Before exporting, tables can be modified within American FactFinder's interface to reorder columns and delete extraneous data. As alternatives to exporting, users are also given the option to print or bookmark/save tables. The bookmark feature creates a unique permalink that can be used to find the table again later.

Because of the wide variety of data available in American FactFinder, it is a valuable resource for academic researchers, economists, business owners, government policy makers, and anyone who is trying to grasp the diverse communities and industries that make up the United States. The variety of search interfaces allows users to access data at a level appropriate to their research needs: from quick facts to detailed datasets. Most importantly, free access means the price is right for any researcher.-Bridget Farrell, Business and Economics Librarian, Auburn University (BRASS Education Committee Member, 2015-2017)

\section{Data.gov: www.data.gov}

The "home of the US government's open data," Data.gov is an online data aggregator created by the US General Services Administration in 2009. Championed by the Obama administration, Data.gov is based on its Open Government Initiative to embrace a new era of open and accountable government. In an age when data are seemingly abundant in our daily lives and with production expanding at an astonishing pace, Data.gov is in its eighth year of bringing data to the American public in an effort to foster government transparency, and is a recognized tool of the open data movement.

Data.gov serves as a portal to aggregate metadata about open data resources published by the federal government; it then harvests and synchronizes source metadata daily. Data from state, local and tribal governments can also be added by agencies for greater user discoverability. Data.gov is built on two open source applications, CKAN (powering the data catalog) and WordPress (driving the Data.gov content), and GitHub maintains its data feeds and application program interface (API) documentation. The more advanced user or developer can access data to create software application machine-readable datasets via APIs or access a JSON (JavaScript Object Notation) open-standard format file describing all datasets.

The Data.gov platform is segmented by six headers: Data (the catalog of government open data); Topics (icons alphabetically displayed for fourteen broad subject areas); Impact (data application examples of "citizens leveraging open data"); Applications (software application tools from business, community and government, mostly at no cost and with no registration); Developers (technology information and updates for developers related to infrastructure, APIs, and open source projects); and, Contact (report a problem, make a request, and ask a question). See the Open Data Stack Exchange to see previous questions asked and answered, or query the Data.gov community.

Select "Data" to search or browse the catalog of over 186,000 datasets aggregated in Data.gov. The heart of the platform, the data catalog identifies government data series, datasets, and a host of tools and products. Catalog search by keyword, order your results (relevance, name, last modified, popular, or date added), then filter the results by location, topics or topic categories, dataset type, tags, formats, organizations or organization types, publishers or bureaus. Select multiple items to focus a search. Displayed results default to those most popularly viewed.

Two recent enhancements help Data.gov and its users. A 2013 Executive Order required that all federal data be published as both machine readable and open data. Then, in 2014-15, there was significant operations restructuring, from dependence on agency-submitted, one-at-a-time datasets to Data.gov becoming a data harvesting hub, which now pulls agency datasets automatically and daily. These significantly more efficient methods enable greater discoverability of data and develop Data.gov as a more credible, reliable portal.

Suggested improvements for Data.gov include the provision of a site index and a data release calendar. In searching, it might be useful to enable a "search within" results option, and allow results to be ordered by date of publication, not just by date added. The metadata are difficult to understand: Different datasets have different metadata structures, metadata files are not well labeled, and there is no complete list of 
metadata fields with descriptions. As well, the Data.gov blog is buried in the footer. The blog exemplifies rich elements of the catalog and recent developments in the Data.gov platform, and would show off well at the header level with Data and Topics. Sadly, the sizeable number of bad links in the catalog make it difficult to access linked data results.

Data.gov carries the responsibility of being among the first government open data portals and, as such, there is public expectation that it provide a framework that goes beyond data delivery. The need to prepare end users to discover forms of data grows, and data visualization is key. While the public is encouraged to "suggest a dataset here" at Data. gov, there is more to it. To sense the power of open data, one might turn to other data sites and tools such as Data USA and Tableau, which have flourished as they involve end users in data discovery.

Yet, Data.gov continues to build on its success, going beyond the simple provision of access to open data, standardizing the requirements for government data provision, and initiating an open door for public inclusion. The platform has spawned a host of data.gov sites in other countries (e.g., Canada, the UK, Australia, France, Singapore), with 106 countries now bringing the open data movement forward, according to a 2016 United Nations global survey.

Still in its infancy, there is no dominant type of user of open data, though the ideals sponsoring the Data.gov tool (transparency, participation, and collaboration) suggest this platform could be a go-to site for US citizens of all kinds. In reality, Data.gov is a much larger effort that exists as a partially fulfilled promise of government data transparency, and can be recommended for viewing and use by all interested in government open data as a work in progress.-Monica Hagan, Business Research and Instruction Librarian, University of California, Los Angeles (BRASS Education Committee Member 2015-2017)

SEC EDGAR: https://www.sec.gov/edgar/searchedgar/com panysearch.html

EDGAR is the Electronic Data Gathering, Analysis, and Retrieving system provided by the US Securities and Exchange Commission (SEC). Since 1993, the EDGAR database has provided free electronic access to millions of corporate filings. Recently, the SEC has updated the EDGAR interface, adding improved (and much needed) search functionality. Investors, companies, and the general public will find EDGAR a useful research tool for maintaining transparency in the corporate sector.

Companies were phased into EDGAR from the paperfiling system over a three-year period, ending May 6, 1996. After this date, all public domestic companies were required to file via EDGAR, with some exceptions. As of November 4, 2002, the SEC required foreign companies to file in EDGAR as well, whereas previously it was optional.

EDGAR provides access to financial statements such as 10-K's, 8-K's, 10-Q's, and proxy statements, which allow investors to decide whether a company's securities are a good investment. See EDGAR's Beginner's Guide to Financial Statements (https://www.sec.gov/investor/pubs/begfinstmt guide.htm) for a detailed description of these documents. EDGAR also provides access to correspondence between filers and EDGAR reviewers dating back to August 2004.

Along with equity and cash flow, financial statements include information about the company's executive compensations policies. This information can be found in forms $10-\mathrm{K}$ and $8-\mathrm{K}$, registration statements, and schedule 14A. Additional filings on mutual funds and annuities can be accessed from the search tools page: https://www.sec.gov ledgar/searchedgar/webusers.htm.

EDGAR also contains information on mergers and acquisitions, as long as one or both of the companies involved are required to file with the SEC. Information on Initial Public Offerings_-including offering documents_can be found in a company's registration statements. If a company has filed for bankruptcy or Chapter 11 reorganization, details can be found on form 8-K.

One of the SEC's goals in designing the new site was to transform the EDGAR database from a "form-based electronic filing cabinet to a dynamic real-time search tool with interactive capabilities." The new interface is simple and clean, allowing users to search by company name, ticker symbol, or a central index key (CIK) number to quickly find information. A CIK number is a unique identifier assigned by the SEC to any company that files disclosure documents in the United States. The EDGAR CIK Lookup, available from the homepage, is a handy tool for those unsure of a company's CIK number.

Search results are listed by date, with the most recent listed first. For a list of the latest filings, see https://www .sec.gov/cgi-bin/browse-edgar?action=getcurrent. Additional searching options and information are accessed by clicking further into the site, a feature that keeps the homepage uncluttered. New features include an RSS feed to see when new filings are added, and export/sharing options on each page. EDGAR is constantly making improvements to their site. To see the most recent changes, check out their search updates page at https://www.sec.gov/edgar/searchedgar/edgar searchupdates.htm.

The free version of EDGAR does not provide real-time access to filings. Users may have to wait up to 24 hours for new listings, and during busy times at the SEC, this wait time may increase.

When using the Companies and Other Filers searchthe most common-use the exact name of the company as reported on the SEC filings, otherwise search results will include companies with similar names. Also, be sure to check whether a statement has been amended; you will see "A" after the filing type name if it has been amended.

The full text search allows users to search the entire text of all SEC filings from the past four years. Understanding the rules and regulations associated with the various filing 


\section{FROM COMMITTEES OF RUSA}

types is a tremendous help when searching in EDGAR. See the Forms List (https://www.sec.gov/forms) for detailed descriptions. To limit search results to certain form types filed by a specific company, use the Companies and Other Filers search. After EDGAR returns the results, narrow the results by form type or year.

EDGAR is a valuable, free resource for anyone interested in researching public companies. The new interface and improved search functionality make it more user-friendly and accessible than ever. It is highly recommended for all libraries._Cara Cadena, Business Librarian, Grand Valley State University, Grand Rapids, Michigan (BRASS Education Committee Member 2015-2017) 